Industrial robots are now a reality. They are having an impact in the field of automation such that they have come to symbolize high-level indus-: trialization of a society. An argument has continued that introducing robot technology causes unemployment. However, as the economy improves with the introduction of the high-level robot technology, several employment opportunities will be opened up. Fortunately, robot technology may provide the only opportunity of developing countries to speed-up offsetting their lack of competitiveness, to narrow down the existing technological gap between them and the industrialized countries, and to bring a bright future for their economies. Therefore, robot technology should receive much more attension.

Robots are defined and a historical background is presented. Existing industrial robots are reviewed and some future prespectives are presented. The sociological and economical impacts of robot technology in the society of man is then studied. A few of the general categories where robots are and can be used are listed. Applications in the fields of industrial automation and energy, specially oil drilling and coal mining, are stutied in some detail. Finally, the urgent needs of developing countries for the - adaptation of the robot technology in order to get to the race and to keep. : their competitiveness is stated. It is hoped that this state-of-the-art: study of robot technology presented here will enhance the introduction and adaptation of this technology.

\title{
INTRODUCTION
}

The word "robot" is derived from the Slavic word "robota", meaning heavy work. However, robots are understood to be machines having the capability of performing complex tasks of a physical and mental nature. Simply, robots can be defined as "automatic intelligent machines". The technology
of robots had been derived during world war II with the advent of nuclear L

*Lecturer, Mechanical Engineering Department, Faculty of Engineering and Technology, El-Minia University, El-Minia, Egypt. 
energy to address the urgent need for remote handling of radioactive materials. To-day, robots are quietly taking their places alongside humans on the production line to raise productivity and to perform the "dirty work". Robots can do most of the work still performed by human as well as dangerous tasks formaly assigned to humans. Furthermore, robots can do new tasks that human cannot do. They can work for thousands of hours with less than two percent down time. Japan, United States, Northern Europe, and Russia had established robot industries with varying degrees of government assistance. Industrial robots are now numbering many thousands in all kinds of industrial applications thoughout the in- dustrialized world. In Japan alone, there are already over 10, 000 - produced and working assembly robots [1]. The public has been saturated with the science fiction concept of robots made famous in the movies. Especially, the so-called domestic robots which can clean the house, answer the door, serve meals, etc. (Fig. I). This domestic robot is really a very basic "teach and repeat" unit which once taught a motion, will simply repeat that motion. However, the concept of industrial robots is stemmed from the human arm. Figure 2 illustrates a human arm model where the shoulder joint is modelled by a ball and socket joint, the elbow by a simple turning joint, and the wrist by a Hooke joint [2]. Such industrial robots are capable of receiving any form of intelligence (human, hydraulic, electrical, or mechanical) and transforming it into a precise movements and measurements. They are adequate for simple repetitive tasks being pursued in industry such as pick and place materials, spot welding, spray painting, and assembly operations.
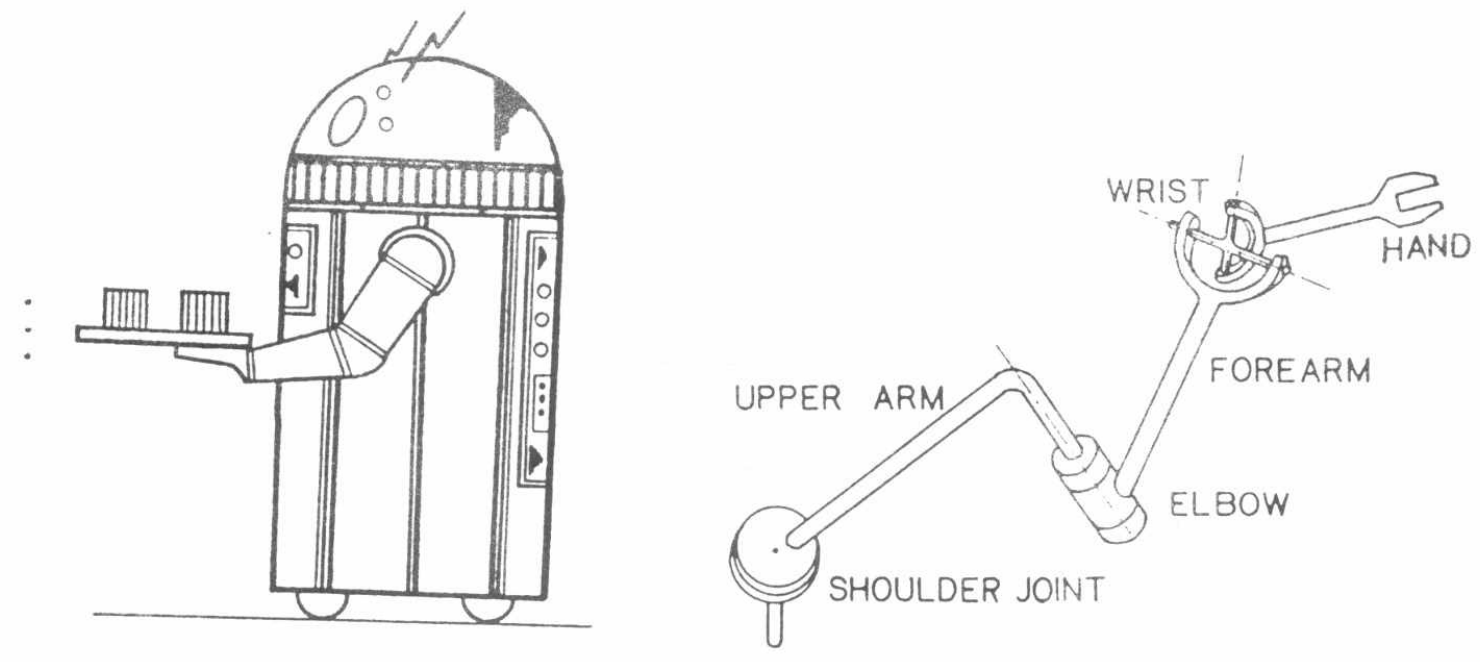

Fig. 1 A domestic robot.

Fig. 2 A human arm model. 


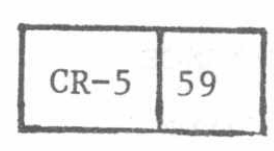

$r$

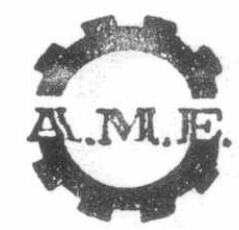

SECOND A.M.E. CONFERENCE

HISTORICAL BACKGROUND

Robots had their origins with the creation of first tools. However, working robots become really possible through the development of controls to keep them performing at least withen acceptable limits. Actually, effective development of robot technology demands integration of disciplines that are frequently considered separate. The primary marriage is of mechanical and electronics engineering disciplines.

The existing industrial robot had its origins in both the teleoperators and the numerically controlled machines. The word "teleoperator" is usually .used to indicate human control of a remote device such as a manipulator [3]. -tele " meaning distant and "operator" referring to something or someone": that performs action, "teleoperator" means performing a task at a distance. Teleoperator systems had been developed during the World war II to handle radioactive materials and had then been applied since 1967 in both the U.S. and the USSR space programs. They can unload payloads from the space cargo bay and perform other tasks in space [4,5]. Figure 3 illustrates the U.S. space shuttle remote manipulator system. Besides human, teleoperator system is usually contains man-machine interface, computational intellif gence, manipulator, sensory hardware, and communication subsystems. Human presence provide the necessary decision making capability which cannot be determined in advance. Master-slave systems are the most common teleoperators. They are characterized by a master controller which is either a scaled replica or a geometrical duplicate of the slave manipulator ( Fig. 4). Several alternative teleoperator systems exist, in most of them the operator controls the manipulator by using either a joystick or a button box device.

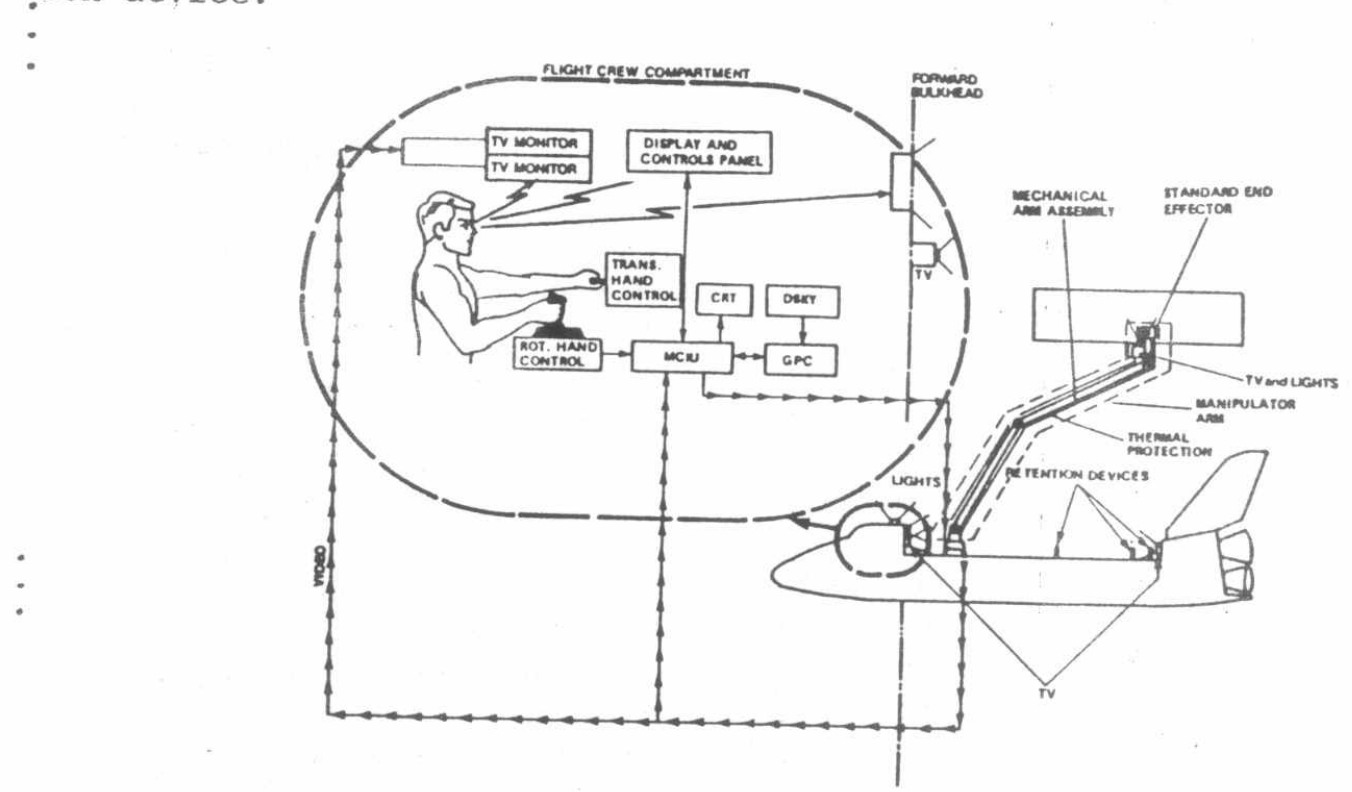

Fig. 3. Shuttle remote manipulator system.

The rapid development of computers and solid state electronics opened entirely new perspectives. The computer is indeed made it possible to equip the robot with a brain, and therefore one can argue that computer-controlled industrial robot represents the first truly general purpose automatic device. The development of industrial robots has been steadily advanced ever since. 


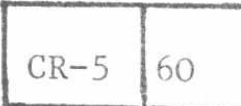

$\Gamma$
SECOND A.M.E. CONFERENCE

6 - 8 May 1986 , Cairo

CURRENT AND FUTURE PROSPECTS

Existing computer-controlled industrial robot consists mainly of a set of rigid links and powered actuated joints ( Fig. 5 ). A computer is then needed and can be programmed in such a manner that it will send the correct signal to the right activating motor in the required sequence and at the appropriate time for locating the end effector, or the hand, at the prescribed position and orientation. Such robots can be readily reprogrammed to do different tasks and therefore will eliminate the need for high cost, custom designed automation equipment.

•

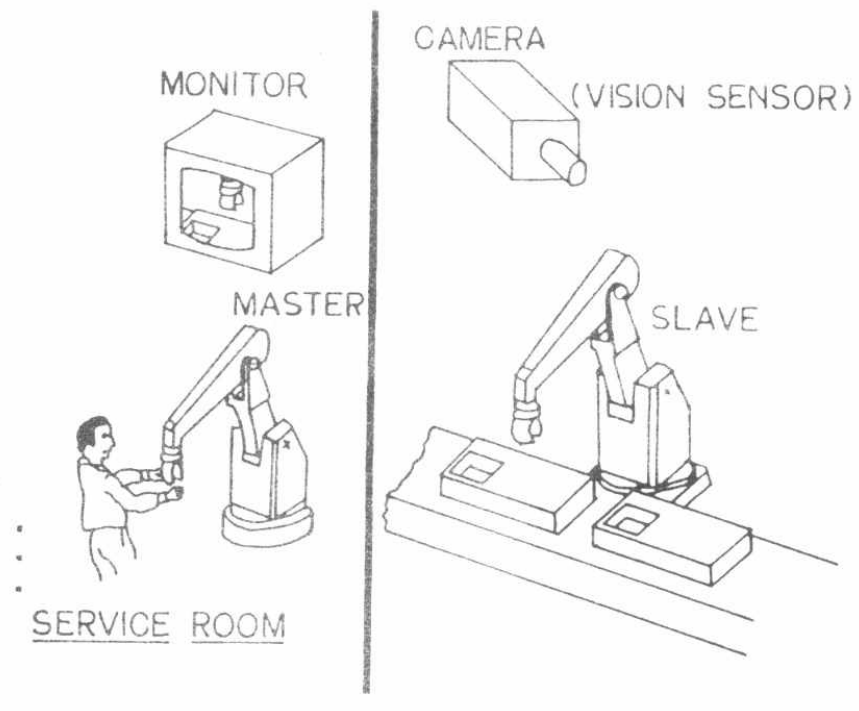

Fig. 4 Master-slave manipulator.

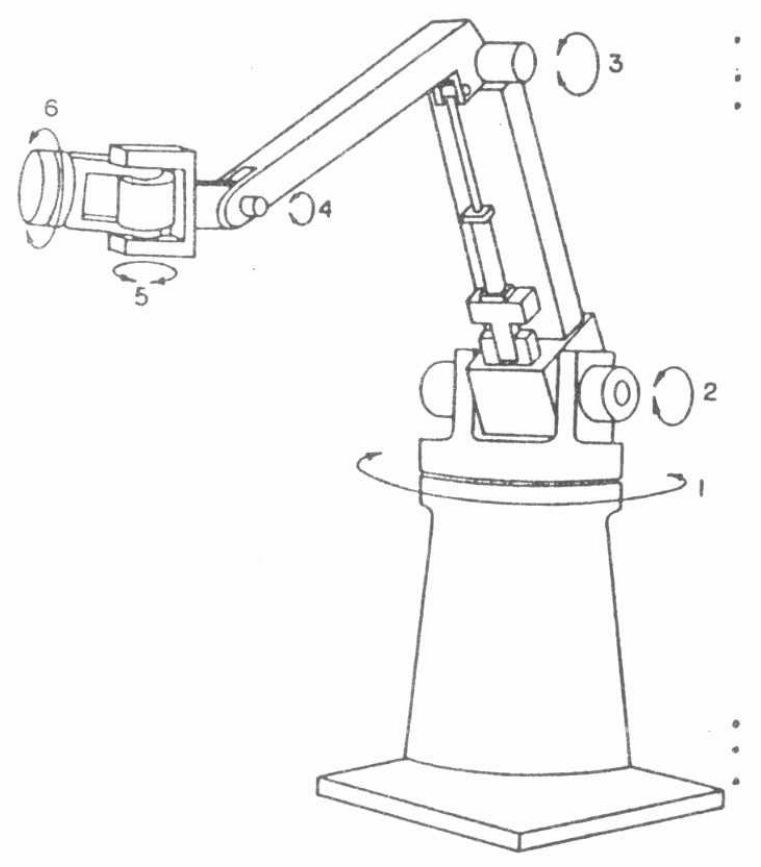

Fig. 5 Cincinatti Milacron $\mathrm{T}^{3}$ manipulator.

Since, no human hand is capable of precision measurement or machining operations under load, most of these industrial robotic arms are accurate to about $1 \mathrm{~mm}$ which is insufficient for many precision operations. Figure 6 illustrates two examples of mechanisms that form adequate bases for more rigid and precise robots $[6,7]$. Some of the existing robots weight - 200 to $500 \mathrm{~kg}$ and they are usually used to pick up 2 to $5 \mathrm{~kg}$ weights. - Therefore, the future generation of robots should be more stiffer, precise, and high speed robots. They also may have sensors to sense unpredictably changing external environments and tasks in order to enable them to incorporate this information, store it, and signal it to the attached computer.

Present industrial needs are deriving towards the integration of flexible automation and, in particular, towards the construction of robotic systems. One or two, or sometimes more, robots are used [8]. The robotic system also includes automated handling, transport, measuring, testing, etc. machines. Figure 7 illustrates an integrated robotic manufacturing system with two robot cells linked together by trasferring conveyors to form a manufacturing line $[9,10]$. The introduction of robotic systems not only 


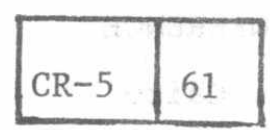

$\Gamma$

reduces the human work force and retooling time, but also gives flexibility for product change and product volume. Other areas that require attention include the development of peripheral equipment such as part supply units -feeders-, hands, and automatic hand change units.

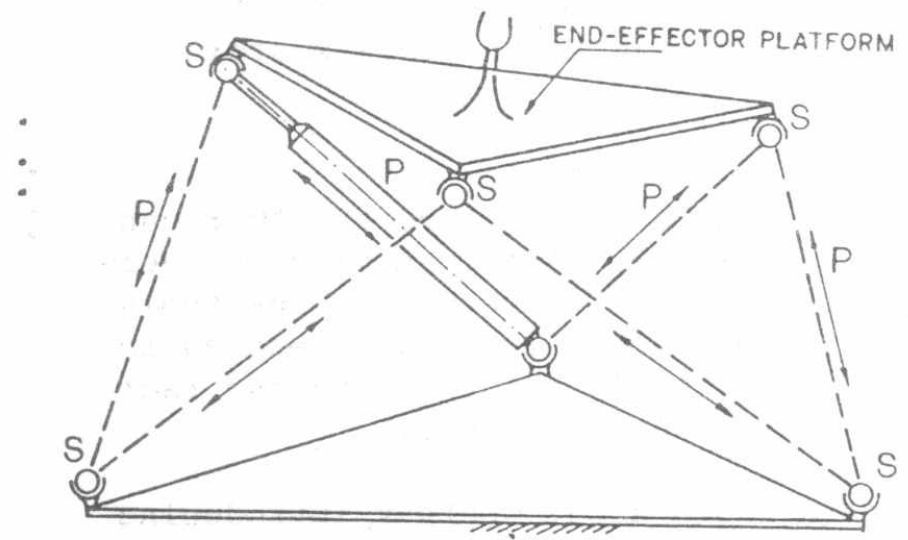

(a) Stewart-platform.

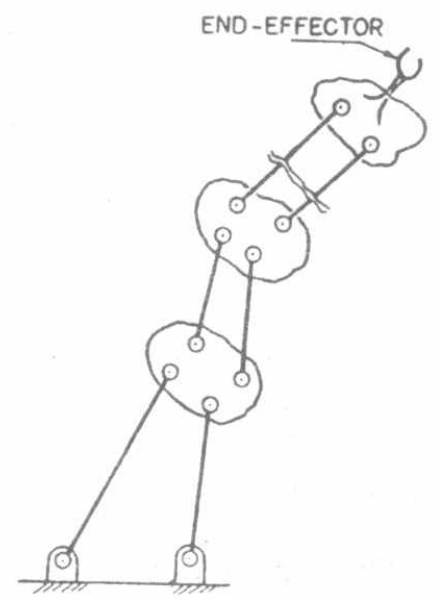

(b) Partially-parallel robotic mechanism.

Fig. 6 Future robotic models.

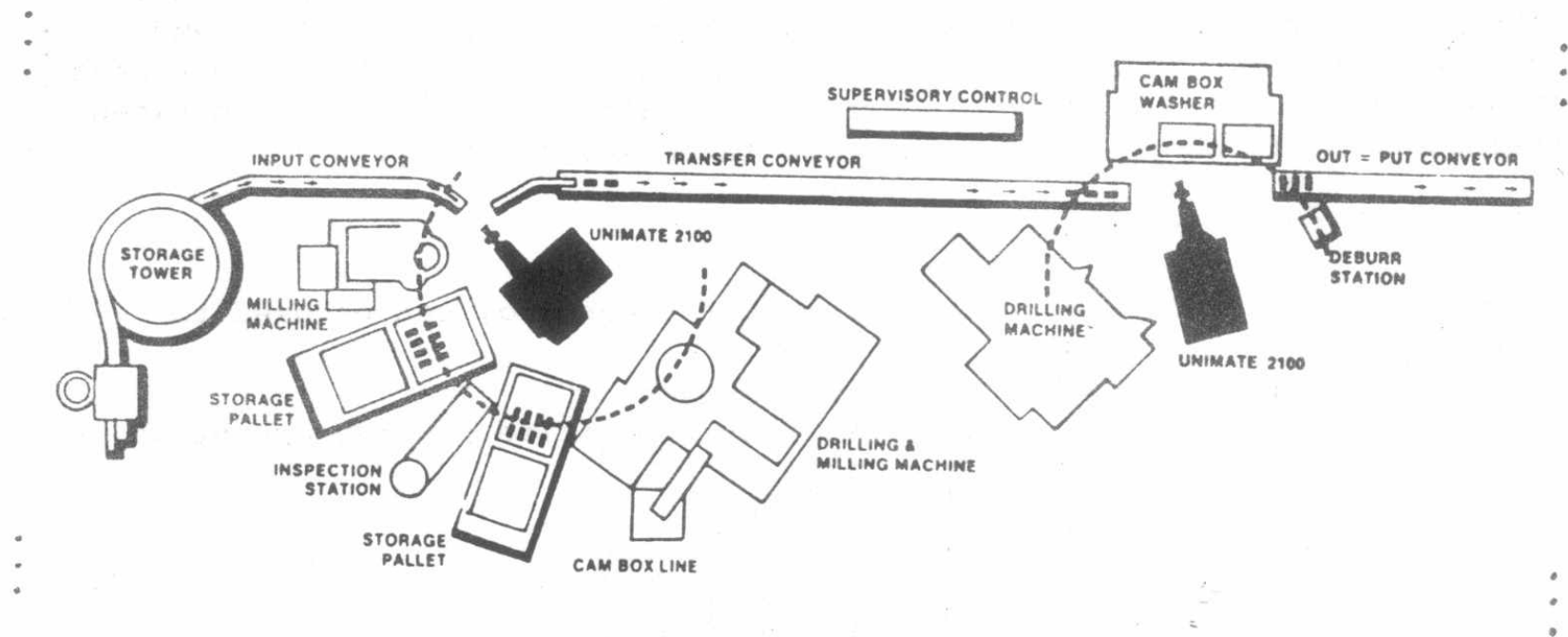

Fig. 7 Integrated robotic manufacturing şystem.

SOCIOLOGICAL AND ECONOMICAL IMPACTS

Human capabilities are in many cases not sufficient to satisfy modern industry requirements of strength, endurance, precision, speed, and the ability to work in hazardous environments. Robots and robotic systems humans. Therefore, such capabilities. In addition, they provide the flexibility of $L$ 


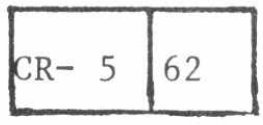

$\Gamma$
SECOND A.M.E. CONFERENCE

6 - 8 May 1986 , Cairo

alongside, if not replacing, humans on the production line.

Sociological and economical benefits of the introduction of robots and robotic systems to the field of automation are really astonishing and worth the high investment cost as well as their social problems. Such benefits can best be summarized in the following items:

- Relieving humans of dangerous, unhealthy, and boring jobs;

- Improving living standards and working hours;

- Reducing accidents and improving safety;

- Reducing production losses; fewer rejects and less waste;

- Improving equipment utilization; and

- Improving product quality.

As an example of the economic benefits of such technology, the American and Japanese markets are compared. Historically, American products were considered to be of good quality. During the 1950's U.S. machine tools were considered the best in the world. Now, not only is Japanese equipment cometitive in quality but in price. This is evidenced by the fact that Japan now produce more than $4 \mathrm{O}_{5}$ of the world's robot.

On the other hand, the argument has continued about whether introducing robot technology causes unemployment [11,12]. One can argue that such technology has the potential to cause economic hardships by reducing the labor force with the resulting unemployment. However, as the economy improves, several employment opportunities will be opened up. Furthermore, the growth of the robotic industry itself provides employment opportunities by creating new jobs either directly or indirectly related to robots, computers, and automation in general. In fact, the United Auto

: Workers membership has favored the introduction of such technology and : productivity [11]. Moreover, in Japan correlation has been found between introduction of robots and the increase in employment [12].

\section{TYPICAL APPLICATIONS}

A few of the general categories where robot technology can be used to benefit the society of man are:

- Operation in hazardous environments;

- Industrial automation especially repetitive precise operatios at all scales of component sizes;

- Fabrication and repair in space;

- Remote operations in space or underwater;

- Oil exploration and production on the ocean floor;

- Energy systems maintenance and repair; and

- Human component replacement.

Each of these general categories can be expanded into numerous subtasks.

Industrial automation is one of the most challenging of all robotic applications because of the complexity and the diversity of the processes it encompasses. Besides machining and insertion or mating of parts, it includes material handling, parts orientation, inspection, material tracking, and man-machine interaction. Industrial robots are and can be used in the following areas:

- Industrial assemblies;

- Machine loading and unloading; 


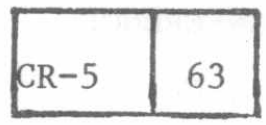

$\Gamma$
SECOND A.M.E. CONFERENCE

6 - 8 May 1986 , Cairo

- Die casting, forging, pressing, and heat treating;

- Grinding, drilling, riveting, and other machining operations;

- Precision light machining: routing, trimming, and deburring while maintaining high tolerance without supporting jigs;

- Welding in vehicle and ship structure;

- Wire solding of leads to micro-chips;

- Painting; and

- Visual inspection.

Figure 8 illustrates the number of robots used in industrial automation in Japan $[13,14]$. It is clear that this number increases year-to-year from .1978 to 1980 .
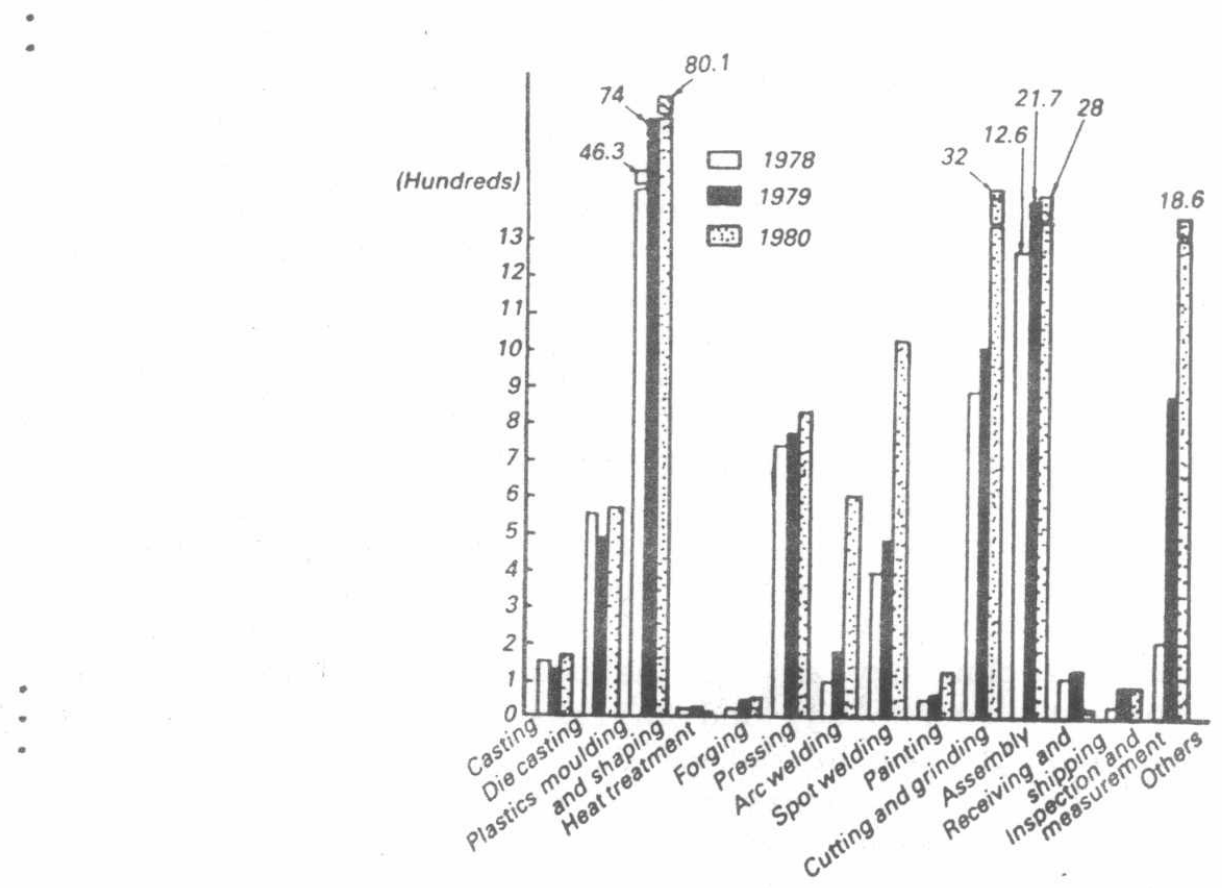

Fig. 8 Number of robots used in Japanese industrial automation.

In the field of energy, robots are and can be also used in the areas of:

- Nuclear reactors:

- inspection, maintenance, and repair of components specially in high radiation zones;

- accident mission capabilities for rescue operations.

- Coal mining:

- inspection, placement and removal of support structures;

- rescue operations.

- Oil drilling:

- inspection, maintenance, and repair of underwater fixtures;

- emergency plugging of blowouts;

- extinguish well head fires.

Coal production is responsible for considerable cost to the human race due 
to black lung disease, a dilemma that could be reduced by developing a "manless" coal mine. With more than 20\% of the world's crude oil coming from offshore sources, the ocean floor has great potential if a means of tapping that potential can be found. As oil and coal represent essential sources of energy as well as of hard currency for the Middle-East countries, introducing robot technology to this part of the world becomes very essential and demanding.

THE URGENT NEEDS OF DEVELOPING COUNTRIES

Developing countries have to realize the seriousness of their economies and - the fact that the technological gap between them and the industrialized - countries is actually widening up. As the industrialized countries move towards improving their technology and consequently their economies, the developing countries continue to fall behined as their technology becomes outdated and their economies fall to respond quickly enough to more efficient competitive forces. However, the opportunity still exist for developing countries to stay in the race and to keep their competitiveness. The high level technology of intelligent, flexible machines as represented by robots and robotic systems which may appear to threaten the developing countries to be driven away from the race, may also provide their only opportunity to speed-up offsetting their lack of competitiveness, to narrow down the technological gap, and to bring a bright future for their economies. Moreover, this technology may block the flow of imigrating local technological talents to the industrialized countries seeking challenging opportunities. Such phenomena best known as the "brain drain", [15]. The developing countries have therefore to catch this life time opportunity and to get in the race of technology as soon as possible. Otherwise, in : this world of fast improving technology and endless inventions, the present: - stage of robot technology will soon be out-of-date and will no longer be: available for developing countries whenever they realize their needs for it. Even if it becomes available, the developing countries will always be dependent on the industrialized countries. Consequently, the hope of the developing countries to be independent and to get to the race of competitiveness will turn almost to a dream.

\section{REFERENCES}

1-Makino, H. and Yamafuji, K., "State-of-the-Art of Automation Assembly in Japan," presented at the 15 th International Assembly Automation, 22-24 May, 1984, Paris.

:2- Sugimoto, K., and. Duffy, J., Final Report on the Geometry of Robot Arms, - DOE Contract No. AC05-79ER-100I3, Univ. of Florida, 1980.

3- Lipken, H., Kinematic Control of a Robotic Manipulator with a Unilateral Manual Controller, M.Sc. Thesis, Univ. of Florida, FL, 1983.

4- Graham, J.D., "The Shuttle Remote Manipulator System," Presented at a Workshop on the Impact on the Academic Community of Required Research Activity for Generalized Robotic Manipulators, at the Univ. of Florida, Gainesville, FL, Feb. 1978.

5- Heer, E., "Prospects for Robots in Space," Robotics Age, Vo1. 1, No. 2, 1979 .

6- Stewart, D., "A Platform with Six Degrees of Freedom," Proc. I. Mech. Engrs., Vol. 180, Pt. 1, No. 15, pp. 371-386, 1965.

7- Mohamed, M.G., Instantaneous Kinematics and Joint Displacement Analysis 


\begin{tabular}{|l|l|}
\hline CR-5 & 65 \\
\hline
\end{tabular}

of Fully-Parallel Robotic Devices, Ph.D. Dissertation, Univ. of Florida, Gainesville, FL, 1983.

8- Makino,H., "An Experimental Approach to NC Assembly Center," Proc. I. Conf. on Production Engineering, Japan Society of Precision Engineering, pp. 486-491, 1971.

9- Beni, G., and Hackwood, S., Recent Advances in Robotics, Interscience Wiley, 1985.

10- Heer, E., "Robots in Modern Industry," Presented in [9], pp. 11-36.

11- Engelberger, J.F., Robotics in Practice, American Management Association, 1981.

. 12- Yonemoto, K., "Robotization of Japanese Industries- Socio-economic

- Impacts by Industrial Robots," Japan Industrial Robot Association, Sept.

- 1984.

13- Niinomi, T., and Matsui, T., "Applications of Robots to Assembly Lines": Presented in Hitachi Review, Vol. 32, No. 5, 1983.

14- Yonemoto, K., "Industrial Robots: Current Trends and Future Prospects," Robot, Vol. 32, pp.5-16, 1981, of Niinomi, [13].

15- Akeel, H.A., "Role of Robotics in Industrial Development," Proc. 3 rd Cairo Univ. MDP Conf., 28-30 Dec., 1985, Cairo, Egypt. 
